\title{
The research publications of members of European national noncommunicable disease health advisory committees
}

\author{
Elena Pallari, Grant Lewison* \\ Department of Cancer Studies, King's College London, Guy's Hospital, Great Maze Pond, London, SE1 6RT, UK
}

\begin{abstract}
This paper describes a new indicator of research impact or influence, namely the research experience of health advisory committee members in 21 European countries, and how this relates to the burden of disease in those countries. Attention is confined to five noncommunicable diseases (NCDs): Cancer, cardiovascular diseases, diabetes, mental disorders, and chronic respiratory diseases, and the 5 years 2009-2013. In 2010, these five disease groups accounted for $57 \%$ of the disease burden in Europe as measured by Disability-Adjusted Life Years. The file of advisers' research papers contained 12,854 biomedical articles and reviews in the Web of Science, of which 5713 were concerned with one or more of the five NCDs. This output was compared with the relative disease burden in the countries concerned, and with the burden from different manifestations of these diseases such as cancer sites and alcoholism and dementia among mental disorders. such as alcoholism and dementia. The extent of other European countries' contributions to the advisers' research portfolios was also determined; it was higher than expected.
\end{abstract}

Keywords: European countries, health advisers, noncommunicable diseases, research outputs

\section{INTRODUCTION}

There is a surprisingly large literature on the way medical research can be used, or better used, by policy-makers, which has expanded rapidly since 2004. Despite this, there appears to remain a gap between the world of research and the world of health policy that has been frequently observed, and lamented. ${ }^{[1-6]}$ Civil servants, who are in many ways the customers for health research, have difficulty in communicating effectively with the research community. ${ }^{[7-9]}$ A survey of the situation in Europe with regard to health

*Address for correspondence:

E-mail: grant.lewison@kcl.ac.uk

\section{Access this article online}

Quick Response Code:

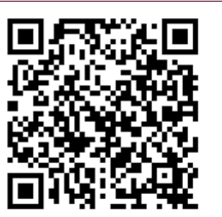

Website:

www.jscires.org

DOI:

10.4103/2320-0057.174864 services research in 2009-2010 revealed a remarkably varied picture and poor use of such research by policy-makers, except with regard to new drugs. ${ }^{[10]}$ One disease area in which public and patient advocacy has, however, seen a remarkable influence on both research and policy has been HIV/AIDS, and there may be lessons that can be applied also to cancer treatment. ${ }^{[1]}$

The role of advisory committees is clearly important, and members' views play a big part in the approval process for new drugs and medical devices by the US Food and Drug Administration. ${ }^{[12]}$ In Germany, advisory committees decide on a policy for medical research involving animals,

This is an open access article distributed under the terms of the Creative Commons Attribution-NonCommercial-ShareAlike 3.0 License, which allows others to remix, tweak, and build upon the work non-commercially, as long as the author is credited and the new creations are licensed under the identical terms.

For reprints contact: reprints@medknow.com

How to cite this article: Pallari E, Lewison $\mathrm{G}$. The research publications of members of European national noncommunicable disease health advisory committees. J Sci Res 2015;4:124-34. 
but since the scientists out-number the animal welfare representatives, the committees have not been able to strike a fair balance between conflicting objectives. ${ }^{[13]}$ However, there seems to have been little other study on the role of health department advisory committees in guiding the policies of their departments, or of whether their research experience plays a role in the allocation of resources in health care in their countries. It would be expected that experts in particular fields would argue for greater priority for patients in their specialty and that they would reinforce the messages disseminated by patient groups. However, we found no evidence on how this process might be occurring.

This project was part of an investigation for the European Union (EU) of the research activities in Europe on five noncommunicable diseases (NCDs): Cancer, cardiovascular diseases (including stroke), diabetes, mental disorders, and respiratory diseases. All NCDs together accounted for some $86 \%$ of the disease burden in Europe in 2010, according to the recently-published Global Burden of Disease compilation. ${ }^{[14]}$ This is measured in Disability-Adjusted Life Years (DALYs), which take into account both early deaths and the impairment of life for those living with a disability. The five NCD studies here were responsible for $57 \%$ of the European total disease burden: Cardiovascular diseases $19.5 \%$, cancer $17.2 \%$, mental disorders $13.2 \%$, respiratory diseases $4.7 \%$, and diabetes $2.5 \%$, though there were considerable variations from country to country, especially in cardiovascular diseases and diabetes.

The investigation aimed to map the outputs of papers (articles and reviews covered in the Web of Science [WoS] for the 12 years, 2002-2013), their funding sources, and their impacts. We created five large files with papers in each NCD: Cancer 282,055 papers; cardiovascular diseases 211,507 papers; diabetes 40,550 papers; mental disorders 138,666 papers; and respiratory diseases 18,822 papers. There are some conventional measures of research impact, such as citation scores, ${ }^{[15-17]}$ recommendations by the F1000 group of expert reviewers ${ }^{[18,19]}$ and percentages of reviews, ${ }^{[20]}$ and we used some of these, but we wanted to explore other indicators to show the influence of the papers on society and on decision-makers in the Member States.

Two useful indicators are the extent to which papers from a country are cited on clinical guidelines ${ }^{[21-24]}$ and are reported in the mass media. ${ }^{[25,26]}$ These are good measures of the utility of the research being undertaken, because the objective of the medical research is to provide information that will enable better treatment of patients, and at least as important, to prevent illness in the first place. (This often involves social interventions, which is why we took papers from both the Science Citation Index Expanded and the Social Sciences Citation Index.) The production and use of clinical guidelines have expanded rapidly since 2008 [Figure 1], and particularly in continental Europe (including Iceland and Ireland). In 1995-2007, these 30 countries (the 28 Member States of the EU, plus Iceland, Norway, and Switzerland, but minus the UK) accounted for 124 of 391 papers (32\%) but in 2008-2015, for 203 of 512 papers (40\%). The analysis of the evidence base of these European clinical guidelines will be presented in separate papers.

The second indicator is the amount of coverage of different medical research papers in newspaper stories in the European countries. Although newspaper print circulations have declined in many countries, they are still very influential as most papers have developed an online presence and can be read on tablets and iPads. They are seen by ministers who set policy, their senior advisers, medical personnel, researchers, and the general public. We recruited a number of research assistants from nearly 20 European countries who could read the stories in the different languages and compile databases of them and the research papers that they cited. This work will also be presented in a separate paper.

A third indicator, the subject of this paper, is the cross-country influence on the knowledge base of healthcare policy advisers in the individual member states. (We originally set out to examine the references on government policy documents, but found that, since they were intended to be read by the general public, they contained pretty pictures rather than scientific references.) We asked our European research assistants to look for and download from the web lists of members of health

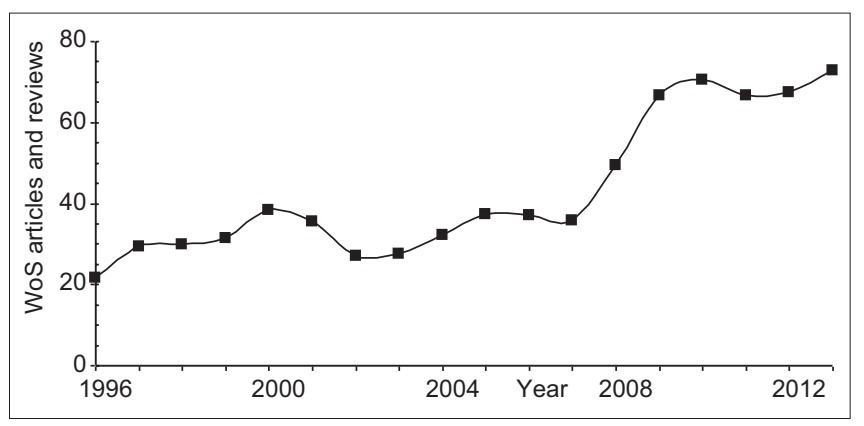

Figure 1: The rise in the number of papers in the Web of Science containing "clinical guidelines" in their title, 1996-2013; 3-year running means 
advisory committees, together with their affiliations and cities. These were to be limited to members during the 5-year period, 2009-2013. We then attempted to list the medical research papers that they had written during these 5 years (articles and reviews in the WoS) so as to create a composite database that could be analyzed, in particular, to show the extent to which these papers were co-authored with researchers from other European countries, and other parameters.

\section{METHODOLOGY}

European health departments have a wide variety of advisory committees, and the membership also varies: Some countries depend mainly on health service administrators and experienced officials while others recruit academics. Particularly in Austria and Germany, most members have the title "Professor Doctor" and sometimes "Professor Doctor Doctor" if they also have a Ph.D., and work at universities. Some of the advisory committees have a wide remit, whereas others are concerned just with a particular disease or health problem, and many of these are not relevant to our study of NCDs. For example, the UK Department of Health has no fewer than 33 Advisory Groups, but only one (on obesity) is relevant to our project, plus one on the end of life, now disbanded. These two groups had 47 members, but only 25 of them published any research papers.

Our research assistants collected together the names of all the health advisory committee members in their countries. However, we found that the names were sometimes listed surname first and sometimes given name (s) first; they all had to be manipulated so that the names were in the format: Verne, $\mathrm{J}$ which is the preferred format for use in the WoS. Furthermore, any letters with diacritical marks (e.g., accents, cedillas, umlauts) needed to be replaced with ordinary roman letters in both the names and the city names. Some of the latter also needed to be changed as they were usually given in the original form, for example, Milano, München, whereas the WoS only uses the Standard English "translations," i.e. Milan and Munich. The names and city names were then concatenated to a simple WoS search statement such as: (CI = Leipzig AND $\mathrm{AU}=($ Brahler, E OR Hegerl, $\mathrm{U}))$ and these were, in turn, concatenated into complex search strategies, typically with up to about 20 search statements.

These were then run against the WoS for the years 2009-2013, and articles and reviews were identified. However, we found that some of the names also had homonyms working in the same cities but on entirely different subjects such as astronomy, ecology, or physics. We therefore used the WoS facility to identify the subject areas of the papers and removed any in these other fields, and ones in areas of medicine with which our project was not concerned, such as gynecology and infectious diseases. This substantially reduced the numbers of papers whose details had to be downloaded to text files. These were then opened by means of a special Excel macro, written by Philip Roe of Evaluametrics Ltd., and selected contents written to an Excel spreadsheet with the following columns [Table 1].

This standard format allowed the committee members' papers from many different countries to be combined in a single Excel spreadsheet for analysis.

The next step was to check that all the papers were relevant to clinical medicine or biomedical research. The source was parsed to isolate the journal name, and this was then looked up electronically in a large thesaurus of journal names that had previously been categorized into one of some dozen major fields such as chemistry, mathematics, and physics (as well as biomedical research and clinical medicine, the two of interest). Papers in any other field were set aside, and if the fields were remote from medicine, the titles were inspected to check if they were relevant. The objective was to narrow the list of papers by the named committee members (and possibly their homonyms) to those that could potentially be relevant to the five NCDs.

The next step in the analysis was to parse the address field, which in the WoS includes all listed addresses, by means of another special macro, again written by Philip Roe, that determined the fractional count of each country on each paper (A paper with one French address and two German ones would be classed as 0.33 for France and 0.67 for Germany.) Papers by Austrian committee members, for example, would be expected all to have at least one Austrian address, but we wanted to know which other countries were contributing to this body of research.

We were not able to find lists of committee members for all the 31 European countries, and some did not appear to have them, so the analysis was confined to 21 countries out of the 31 [Table 2].

We also wanted to see what level of research formed the background of the advisory committee members. This is a decimal number between 1.0 (clinical observation) and 
Table 1: Spreadsheet column headings produced by macro from text files of downloaded paper details created by Web of Science

\begin{tabular}{lll}
\hline Column & Heading & Meaning \\
\hline A & Index & Standard ordinal \\
B & Download & Identifies country \\
C & Authors & Format: Verne-J \\
D & Title & Of paper \\
E & Source & J'nal, year, vol, iss, pp \\
F & DocType & Article or Review \\
G & Addresses & All, separated by (/) \\
H & CU PUB & Publisher country \\
I & Year & Of publication \\
J & Month & Of publication \\
K & LA & Language \\
L & EM & Corresponding author email \\
M & FU & Funding sources \\
N & FX & Funding acknowledgement \\
O & C1 & Authors tagged with addresses \\
P & AF & Author full names \\
\hline
\end{tabular}

Table 2: List of European countries used in this study with their digraph International Organization for Standardization codes

\begin{tabular}{lc}
\hline Country & Code \\
\hline Austria & $\mathrm{AT}$ \\
Bulgaria & $\mathrm{BG}$ \\
Croatia & $\mathrm{HR}$ \\
Cyprus & $\mathrm{CY}$ \\
Czech Republic & $\mathrm{CZ}$ \\
Denmark & $\mathrm{DK}$ \\
Estonia & $\mathrm{EE}$ \\
Finland & $\mathrm{FI}$ \\
France & $\mathrm{FR}$ \\
Germany & $\mathrm{DE}$ \\
Hungary & $\mathrm{HU}$ \\
Ireland & $\mathrm{IE}$ \\
Italy & $\mathrm{IT}$ \\
Lithuania & $\mathrm{LT}$ \\
Luxembourg & $\mathrm{LU}$ \\
Netherlands & $\mathrm{NL}$ \\
Poland & $\mathrm{PL}$ \\
Portugal & $\mathrm{PT}$ \\
Spain & $\mathrm{ES}$ \\
Switzerland & $\mathrm{CH}$ \\
United Kingdom & $\mathrm{UK}$ \\
\hline
\end{tabular}

4.0 (basic research) and is based on whether the papers have "clinical" or "basic" words in their titles. ${ }^{[27]}$ It can be applied to the individual papers forming a country group (RL p), or to all the papers in a given journal in which the papers of interest have been published (RL j). The titles of the papers in the spreadsheet were then parsed by yet another macro to show which were "basic," which were "clinical," and which were "both."
The next piece of analysis was more complex, and involved a comparison of the papers in the combined spreadsheet with the ones in the five NCD files referred to earlier. We assumed that the advisory committee papers would have had an address in Europe, even though a few committee members had addresses in another EU Member State, and performed a look-up function so as to identify which papers were in cancer, diabetes, etc. This would allow us to see the balance of the expertise available to the Member State governments. The look-up not only provided information on which papers were in each of the five NCDs, but also the sub-fields within them. These were of two kinds: Applications or manifestations, and types of research. Applications are the individual diseases or disorders, for example, breast or lung cancer, or alcoholism or depression among mental disorders. Types of research include drug therapy, epidemiology, genetics and surgery; they vary according to the NCD as not all would be relevant. In this study, only the types of research in cancer were analyzed. Because some of the members' papers were in medical fields, but not those of the five NCDs, we used as a denominator the sum of the numbers of papers in any of the five so that the balance of expertise within the group of five NCDs could be seen.

The numbers of papers from committee members of each European country varied greatly, and did not necessarily correlate with the amount of research undertaken by the country, or its size or wealth. Thus, Germany had approximately 2000 papers but the UK only about 400 . For some countries, it was worthwhile to carry out quite a full analysis of the papers forming its advisory committees' portfolios, but for others the analysis was much simpler - Luxembourg, for example, had only four papers, but all were co-authored internationally. Hungary had five specialist committees whose members came from the particular voluntary organizations for the five NCDs.

\section{RESULTS: OVERALL AND MEASURES OF CO-AUTHORSHIP}

The file of papers by the advisory committee members comprised 12,854 articles and reviews, and the distribution by country is shown in Table 3 . The first result is that for most countries (all except for Germany, Spain, the UK, and Finland) the contribution from other European countries is greater than from the rest of the world, whereas typically Europe publishes between $35 \%$ and $45 \%$ of the world total in most biomedical fields. So one might expect that the Rest of the World would have contributed about half as much 
again as Europe. Even in Finland, the most extreme case, the ratio is $<1.32$. Hence, we may conclude that the health committee advisers are better connected to colleagues in Europe (and are therefore benefiting from their expertise) than to those from elsewhere. Overall, "other European countries" contributed 1801 papers to the committee members' outputs compared with "rest of the world" tally of 1017 papers, both on a fractional-count basis.

The papers were fairly clinical, and the mean research level (RL) did not vary greatly between subject areas (the five NCDs) or between countries. The results are shown in Figure 2, both for the five NCDs and for eight countries for which there were 700 papers or more in total. These results were just for those papers in the five NCDs, that is 5713 papers out of 12,854 , or $44 \%$. The papers had a RL averaging 1.49 which was invariably lower (i.e., more clinical) than the average for the journals in which they were published (1.74). Cancer and diabetes research were the most basic, as was that of the advisers in Italy, Spain, Hungary, and the Czech Republic.

We next examined how well the five NCDs were represented among these advisers' portfolios. The papers in the file were all matched against the NCD output files, and the numbers in each of the five NCDs are shown in Table 4, where they are compared with overall European research outputs and the European disease burden from the five NCDs.

It appears from Table 4 that there is less research experience than would be merited in cardiovascular and respiratory diseases and as a corollary, more than proportionate in diabetes and cancer. However, this is for Europe as a whole, and the situation is perhaps different for individual countries. It is only worth performing this analysis for countries with a large number of papers, and we have limited it to countries with at least 700 papers, i.e., the top eight in Table 3.

The table generally confirms the findings for Europe mentioned above, but there are some exceptions. In diabetes Germany is under-represented. In oncology the Netherlands is; on the other hand, it is over-represented in respiratory diseases. Italy is under-represented in mental disorders, as is the Netherlands, but Hungary is over-represented here.

\section{RESULTS FOR CANCER}

The numbers of papers are great enough to allow an analysis of the main cancer sites (manifestations) and types

\begin{tabular}{|c|c|c|c|c|c|c|c|}
\hline Country & Members & Papers & Own & EUR & EUR, \% & 6 Row & Row, \% \\
\hline $\mathrm{NL}$ & 83 & 2554 & 1949 & 397 & 15.5 & 208 & 8.2 \\
\hline $\mathrm{DE}$ & 125 & 2010 & 1715 & 142 & 7.1 & 153 & 7.6 \\
\hline AT & 189 & 1384 & 976 & 276 & 19.9 & 132 & 9.5 \\
\hline $\mathrm{HU}$ & 247 & 1311 & 921 & 246 & 18.8 & 144 & 11.0 \\
\hline ES & 46 & 1179 & 1053 & 60.5 & 5.1 & 65.3 & 5.5 \\
\hline CZ & 51 & 969 & 732 & 176 & 18.2 & 60.7 & 6.3 \\
\hline IT & 107 & 965 & 808 & 94.2 & 9.8 & 62.7 & 6.5 \\
\hline PL & 60 & 794 & 671 & 71.6 & 9.0 & 51.3 & 6.5 \\
\hline UK & 35 & 403 & 340 & 29.8 & 7.4 & 33 & 8.2 \\
\hline EE & 106 & 347 & 188 & 123 & 35.4 & 36.5 & 10.5 \\
\hline FR & 46 & 294 & 233 & 38.5 & 13.1 & 22.8 & 7.8 \\
\hline LT & 89 & 145 & 119 & 21.2 & 14.6 & 4.5 & 3.1 \\
\hline $\mathrm{CH}$ & 39 & 141 & 63.1 & 64.6 & 45.8 & 13.3 & 9.4 \\
\hline DK & 42 & 111 & 95.7 & 12 & 10.8 & 3.3 & 3.0 \\
\hline $\mathrm{FI}$ & 16 & 100 & 65 & 15.1 & 15.1 & 19.9 & 19.9 \\
\hline PT & 16 & 51 & 48.9 & 2.1 & 4.1 & 0 & 0.0 \\
\hline $\mathrm{HR}$ & 19 & 39 & 25 & 12.6 & 32.3 & 1.4 & 3.6 \\
\hline $\mathrm{CY}$ & 26 & 36 & 18.4 & 13.7 & 38.1 & 3.9 & 10.8 \\
\hline IE & 49 & 10 & 5.85 & 3.22 & 32.2 & 0.93 & 9.3 \\
\hline BG & 9 & 7 & 7 & 0 & 0.0 & 0 & 0.0 \\
\hline LU & 31 & 4 & 1.58 & 2.22 & 55.5 & 0.2 & 5.0 \\
\hline
\end{tabular}

Table 4: Numbers of papers in the advisers' overall portfolio of research in each of the five noncommunicable diseases (advisers), and comparison with EUR31 research output in 2009-2013, and disease burden in 2010 in EUR31 countries (thousand disability-adjusted life years)

\begin{tabular}{lcccccc}
\hline NCD & Advisers & Percentage & $\begin{array}{c}\text { EUR31 } \\
\text { papers }\end{array}$ & $\begin{array}{c}\text { EUR31, } \\
\%\end{array}$ & $\begin{array}{c}\text { DALYs, } \\
\mathbf{k}\end{array}$ & $\begin{array}{c}\text { DALYs } \\
\text { \% }\end{array}$ \\
\hline CARDI & 1345 & 23.0 & 101,212 & 29.9 & 28,573 & 34.2 \\
DIABE & 489 & 8.4 & 20,018 & 5.9 & 3610 & 4.3 \\
MENTH & 1217 & 20.8 & 71,437 & 21.1 & 19,290 & 23.1 \\
ONCOL & 2540 & 43.4 & 136,152 & 40.3 & 25,193 & 30.2 \\
RESPI & 256 & 4.4 & 9269 & 2.7 & 6854 & 8.2 \\
Sum & 5847 & 100.0 & 338,088 & 100.0 & 83,520 & 100.0 \\
\hline
\end{tabular}

DALYs $=$ Disability-adjusted life years, NCD $=$ Noncommunicable disease, CARDI $=$ Cardiovascular diseases, DIABE $=$ Diabetes, $\mathrm{MENTH}=$ Mental disorders, ONCOL=Cancer, RESPI $=$ Respiratory diseases

of research. We confined the analysis to the eight countries in Table 5, to six leading cancer sites: colorectal (COL), lung (LUN), breast (MAM), pancreas (PAN), prostate (PRO) and stomach (STO); to three treatment methods: chemotherapy (CHEM), radiotherapy (RADI) and surgery (SURG); and to two other research types, genetics (GENE) and pathology (PATH). Figure 3 compares the disease burden from the individual cancers with the output of research by the advisers, relative to all 


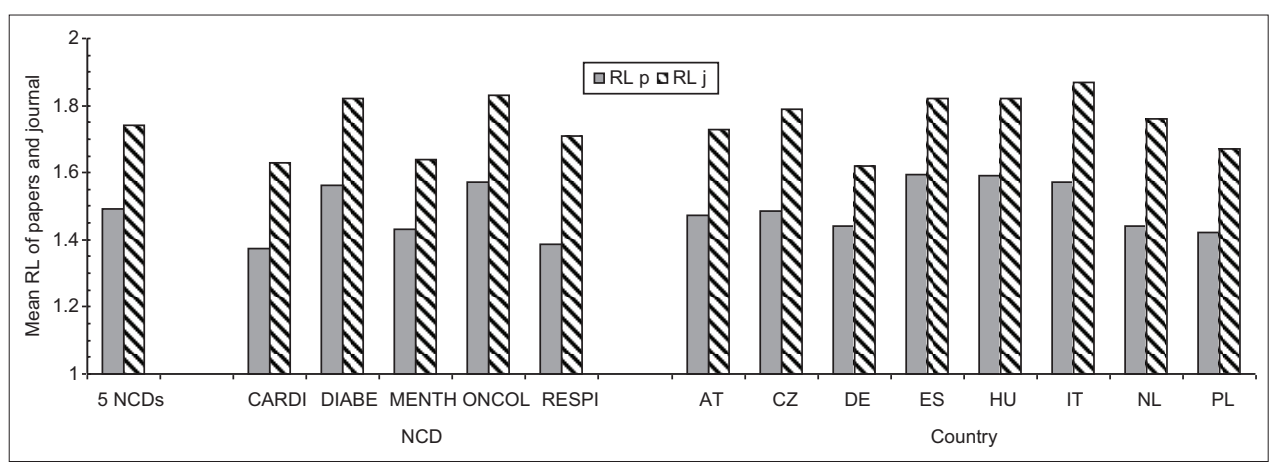

Figure 2: Mean research level of papers from members of health advisory committees in five noncommunicable diseases and from eight European Union Member States. RL p is based on individual paper titles; RL $j$ on the RL of journals in which they were published

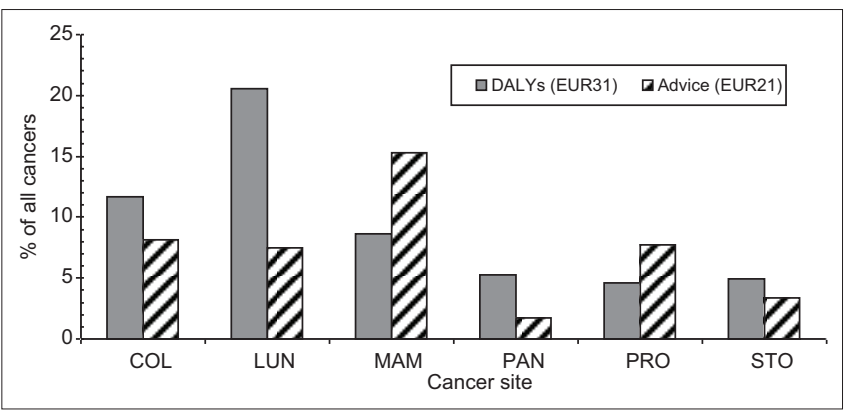

Figure 3: Comparison of disease burden from six common cancers in EUR31, 2010, with the amount of research from the health committee advisers in EUR21 countries, 2009-2013

cancers, and Table 6 shows the analysis of the outputs of the advisers in the eight countries.

This shows the frequently-found imbalance for lung and breast cancers. The former is under-researched and the latter over-researched, in relation to all cancers, but also pancreatic cancer does not get as much attention from the advisers as it would appear to merit whereas prostate cancer receives proportionately more attention.

There is much less variation in the disease burden from these six cancers across Europe, except that prostate cancer is relatively less of a burden in the three Eastern European countries (Poland and Hungary, and to a less extent the Czech Republic), perhaps because the life expectancy of their men is lower, so the lack of expertise among advisory committee members is understandable. Hungary and Poland suffer relatively more from lung cancer, and their advisers' expertise in the subject is clearly extensive and relevant. There are some surprising differences in expertise in different research types, with Germany and Italy strong in surgery, but the Netherlands rather weak in several treatment types.

\section{RESULTS FOR MENTAL DISORDERS}

The second sub-field analysis that we conducted was of different manifestations of mental disorders. These differ greatly from one another, and there is likely to be less carry-across of expertise in the different manifestations than for some other disease areas. Figure 4 shows the percentages of DALYs and of research for six different mental disorders, both as fractions of the total due to mental disorders. These are an addiction (ADD), alcoholism (ALC), Alzheimer's disease and other dementias (ALZ), anxiety and panic disorders (ANX), unipolar depression (DEP) and schizophrenia (SCH). The addictions, alcoholism, anxiety disorders, and depression appear to be receiving less attention than they need, but schizophrenia has much research experience among the advisers compared with its burden.

The numbers of papers are much smaller than for cancer, and some countries in Table 7 appear to have unbalanced advice from their health committee advisers if it is based on their research experience. The dementias are well researched by the advisers in Spain, Italy and the Czech Republic, and schizophrenia in Austria. However in some countries, there is almost no research experience in mental disorders among its advisers, notably Italy (except for dementia).

\section{RESULTS FOR CARDIOVASCULAR DISEASE}

The third analysis was of cardiovascular diseases, including cerebrovascular disease (stroke). The definitions that we used to create sub-fields of CARDI do not correspond accurately to the data for disease burden, but it is instructive first to see how the percentages of papers from advisers compare with the overall disease burden from 
Table 5: Comparison of the size of health advisers' research portfolios in eight European countries in five noncommunicable diseases with the countries' relative disease burden from these noncommunicable diseases

\begin{tabular}{|c|c|c|c|c|c|c|c|c|c|c|}
\hline & \multicolumn{5}{|c|}{ Papers by committee members } & \multicolumn{5}{|c|}{ kDALYs in 2010} \\
\hline & CARDI & DIABE & MENTH & ONCOL & RESPI & CARDI & DIABE & MENTH & ONCOL & RESPI \\
\hline \multicolumn{11}{|c|}{ Numbers } \\
\hline AT & 102 & 45 & 143 & 371 & 15 & 411 & 72 & 321 & 361 & 109 \\
\hline $\mathrm{CZ}$ & 185 & 40 & 101 & 288 & 6 & 758 & 79 & 313 & 583 & 110 \\
\hline DE & 174 & 22 & 284 & 587 & 15 & 4630 & 638 & 3169 & 4268 & 1068 \\
\hline ES & 116 & 36 & 91 & 263 & 39 & 1783 & 395 & 1644 & 1934 & 526 \\
\hline $\mathrm{HU}$ & 165 & 68 & 185 & 293 & 42 & 994 & 106 & 329 & 661 & 155 \\
\hline IT & 94 & 22 & 33 & 245 & 8 & 3008 & 516 & 2109 & 3010 & 678 \\
\hline NL & 241 & 136 & 144 & 149 & 108 & 608 & 84 & 725 & 829 & 229 \\
\hline $\mathrm{PL}$ & 137 & 55 & 67 & 169 & 8 & 2838 & 303 & 1394 & 1953 & 476 \\
\hline \multicolumn{11}{|c|}{ Percentage } \\
\hline AT & 15.1 & 6.7 & 21.2 & 54.9 & 2.2 & 32.3 & 5.7 & 25.2 & 28.3 & 8.6 \\
\hline$C Z$ & 29.8 & 6.5 & 16.3 & 46.5 & 1.0 & 41.1 & 4.3 & 17.0 & 31.6 & 6.0 \\
\hline $\mathrm{DE}$ & 16.1 & 2.0 & 26.2 & 54.3 & 1.4 & 33.6 & 4.6 & 23.0 & 31.0 & 7.8 \\
\hline ES & 21.3 & 6.6 & 16.7 & 48.3 & 7.2 & 28.4 & 6.3 & 26.2 & 30.8 & 8.4 \\
\hline $\mathrm{HU}$ & 21.9 & 9.0 & 24.6 & 38.9 & 5.6 & 44.3 & 4.7 & 14.7 & 29.4 & 6.9 \\
\hline IT & 23.4 & 5.5 & 8.2 & 60.9 & 2.0 & 32.3 & 5.5 & 22.6 & 32.3 & 7.3 \\
\hline $\mathrm{NL}$ & 31.0 & 17.5 & 18.5 & 19.2 & 13.9 & 24.6 & 3.4 & 29.3 & 33.5 & 9.3 \\
\hline PL & 31.4 & 12.6 & 15.4 & 38.8 & 1.8 & 40.8 & 4.4 & 20.0 & 28.0 & 6.8 \\
\hline
\end{tabular}

Cells in lower left section tinted pink if $\%$ of research $<0.5 \times$ percentage of DALYs; pale yellow if $<0.71 \times$ percentage of DALYs; pale green if $>1.41 \times$ percentage of DALYs; bright green if $>2 \times$ percentage of DALYs. CARDI $=$ Cardiovascular diseases, DIABE $=$ Diabetes, MENTH $=$ Mental disorders,

ONCOL $=$ Cancer, $\mathrm{RESPI}=$ Respiratory diseases, $\mathrm{DALY} S=$ Disability-adjusted life years

Table 6: Numbers of cancer papers on six leading sites and of five research types published by health committee advisers in eight European countries, 2009-2013

\begin{tabular}{|c|c|c|c|c|c|c|c|c|c|c|c|c|}
\hline Papers & COL & LUN & MAM & PAN & PRO & STO & CHEM & RADI & SURG & GENE & PATH & All \\
\hline AT & 10 & 19 & 100 & 2 & 35 & 4 & 58 & 23 & 18 & 103 & 33 & 371 \\
\hline$C Z$ & 21 & 5 & 29 & 6 & 12 & 10 & 25 & 14 & 48 & 78 & 29 & 288 \\
\hline $\mathrm{DE}$ & 35 & 27 & 50 & 18 & 115 & 22 & 87 & 34 & 153 & 83 & 48 & 587 \\
\hline ES & 42 & 26 & 27 & 4 & 12 & 17 & 51 & 18 & 16 & 61 & 26 & 263 \\
\hline HU & 26 & 47 & 70 & 2 & 16 & 4 & 52 & 21 & 21 & 86 & 76 & 293 \\
\hline IT & 11 & 3 & 35 & 2 & 2 & 7 & 45 & 11 & 59 & 35 & 25 & 245 \\
\hline NL & 14 & 3 & 42 & 0 & 1 & 6 & 4 & 4 & 18 & 20 & 5 & 149 \\
\hline PL & 13 & 49 & 11 & 8 & 0 & 11 & 31 & 8 & 24 & 44 & 11 & 169 \\
\hline EUR22 & 206 & 191 & 389 & 43 & 197 & 86 & 370 & 138 & 377 & 537 & 259 & 2540 \\
\hline
\end{tabular}

Cells tinted pink if numbers of papers $<0.5 \times$ European average for cancer; pale yellow if numbers. $<0.71 \times$ average; pale green if $>1.41 \times$ average; bright green if $>2.0 \times$ average. For country codes, see Table 2. $C O L=$ Colorectal, $L U N=L$ ung, MAM $=$ Breast, PAN $=$ Pancreas, $P R 0=$ Prostate, ST0 $=$ Stomach, $\mathrm{CHEM}=$ Chemotherapy, RADI $=$ Radiotherapy, $\mathrm{SURG}=$ Surgery, GENE= Genetics, PATH $=$ Pathology

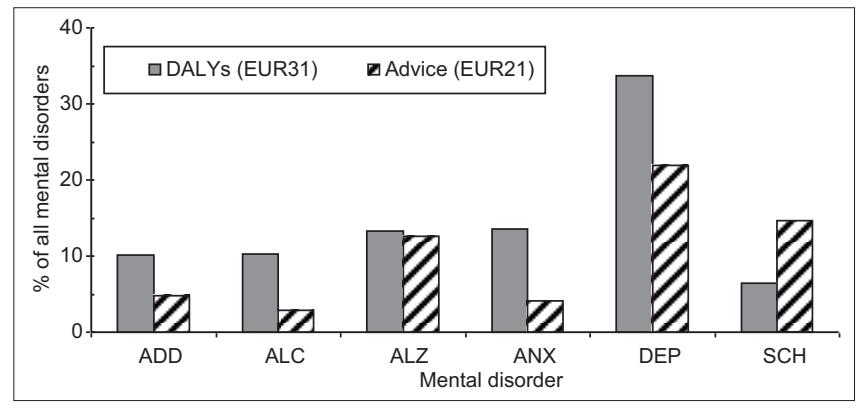

Figure 4: Comparison of disease burden from six mental disorders in EUR31, 2010, with the amount of research from the health committee advisers in EUR21 countries, 2009-2013 cardiovascular diseases, which varies much more than that from cancer. The data are in Table 5.

The three eastern European "accession" countries that were socialist until 1989 and joined the EU in May 2004 clearly have much higher levels of cardiovascular disease than the others, but the correlation between DALYs and papers shown in Table 5 is almost nil $\left(r^{2}=0.02\right)$. The Netherlands is the only one of the eight countries that have more research experience among its health advisers than cardiovascular disease would warrant and contrasts with Germany and Hungary, which have less than half as much as would be proportionate. 
Table 7: Comparison of disease burden from six mental disorders with the research outputs of health committee advisers in eight European countries ${ }^{[28]}$

\begin{tabular}{|c|c|c|c|c|c|c|c|c|c|c|c|c|c|c|}
\hline & \multicolumn{7}{|c|}{ Percentage of all DALYs } & \multicolumn{7}{|c|}{ Papers by advisers } \\
\hline & ADD & ALC & ALZ & ANX & DEP & $\mathrm{SCH}$ & MENTH & ADD & ALC & $A L Z$ & ANX & DEP & $\mathrm{SCH}$ & All \\
\hline AT & 1.7 & 1.6 & 1.7 & 1.4 & 4.9 & 0.8 & 14.1 & 23 & 3 & 19 & 3 & 13 & 44 & 143 \\
\hline $\mathrm{CZ}$ & 0.7 & 0.7 & 1.0 & 1.9 & 3.2 & 0.8 & 10.0 & 3 & 0 & 20 & 0 & 17 & 26 & 101 \\
\hline DE & 1.1 & 1.5 & 2.3 & 1.8 & 4.6 & 0.8 & 13.6 & 2 & 11 & 15 & 10 & 85 & 58 & 284 \\
\hline ES & 1.9 & 0.8 & 2.7 & 1.2 & 4.8 & 1.0 & 14.4 & 6 & 2 & 29 & 4 & 6 & 9 & 91 \\
\hline HU & 0.6 & 1.0 & 1.7 & 1.6 & 2.6 & 0.7 & 9.3 & 8 & 2 & 21 & 8 & 38 & 25 & 185 \\
\hline IT & 1.4 & 0.4 & 0.9 & 1.4 & 4.8 & 0.8 & 11.4 & 2 & 1 & 16 & 0 & 3 & 4 & 33 \\
\hline NL & 1.0 & 1.1 & 0.9 & 2.0 & 7.8 & 0.8 & 15.4 & 7 & 8 & 17 & 8 & 34 & 8 & 144 \\
\hline PL & 1.0 & 2.1 & 0.7 & 1.9 & 3.5 & 0.8 & 11.4 & 2 & 2 & 9 & 3 & 32 & 3 & 67 \\
\hline EUR & 1.3 & 1.3 & 1.7 & 1.7 & 4.3 & 0.8 & 12.9 & 59 & 35 & 153 & 50 & 266 & 178 & 1217 \\
\hline
\end{tabular}

Cells tinted pink if numbers of papers $<0.5 \times$ European average for mental disorders; pale yellow if numbers. $<0.71 \times$ average; pale green if $>1.41 \times$ average; bright green if $>2.0 \times$ average. For country codes, see Table 2. ADD $=$ Addiction, $A L C=$ Alcoholism, $A L Z=$ Alzheimer's, $A N X=A n x i e t y, D E P=D e p r e s s i o n$, $\mathrm{SCH}=$ Schizophrenia, MENTH=Mental disorders, DALYs=Disability-adjusted life years

Table 8 shows the distribution of papers between six leading subject areas, with 150 or more papers from all the countries. The subjects are arterial disease including atherosclerosis and aortic aneurysms (ART); cerebrovascular disease (stroke, CER); ischemic heart disease including acute myocardial infarction (ISC); arrhythmias, including atrial fibrillation (ARR); hypertension (HYP); and heart failure (FAI).

The distribution of cardiac expertise is very unbalanced, with Austria showing to advantage in hypertension (HYP) and cerebrovascular disease (CER) but not in heart failure (FAI), and Italy relatively very strong in arterial disease (ART) but weak elsewhere.

\section{RESULTS FOR RESPIRATORY DISEASE}

The final analysis is of two respiratory diseases, asthma (AST), and chronic obstructive pulmonary disease (COPD) (COP). These account for 1.1\% and 2.9\% of all European DALYs, so the latter is much more serious, but receives less research attention. ${ }^{[29]}$ There are also fewer research papers on COPD from the advisers (107) than ones on asthma (131). In Table 9, the comparison is with the total numbers of papers from each country in the five NCDs because respiratory medicine is dominated by these two diseases - the main other one being cystic fibrosis, but there are only 12 papers on this disease in the database. There is a relative lack of research expertise in respiratory diseases generally, and particularly in COPD with the conspicuous exceptions of the Netherlands and Spain. Spain has a lower relative disease burden from these two diseases together than any other country in "Western" Europe except for Finland, and this may be as a result of having much expertise in COPD (but not in asthma).
Table 8: Research outputs in six subject areas within cardiovascular diseases from health committee advisers in eight European Member States, 2009-2013

\begin{tabular}{llllllll}
\hline Subject & ART & CER & ISC & ARR & HYP & FAI & All
\end{tabular}

\begin{tabular}{lllllll|l|l|}
\hline AT & 16 & 33 & 12 & 7 & 27 & 1 & 102
\end{tabular}

$\begin{array}{lllllllll}\mathrm{CZ} & 19 & 44 & 19 & 48 & 23 & 24 & 185\end{array}$

\begin{tabular}{ll|lll|l|l|l} 
DE & 35 & 13 & 29 & 10 & 25 & 42 & 174
\end{tabular}

$\begin{array}{llllllll}\text { ES } & 20 & 18 & 20 & 25 & 21 & 10 & 116\end{array}$

$\begin{array}{lllllllll}\mathrm{HU} & 34 & 16 & 31 & 42 & 14 & 16 & 165\end{array}$

\begin{tabular}{l|lll|l|l|l|l} 
IT & 50 & 13 & 10 & 1 & 3 & 3 & 94
\end{tabular}

$\begin{array}{llllllll}\text { NL } & 41 & 36 & 32 & 18 & 41 & 36 & 241\end{array}$

\begin{tabular}{l|l|l|l|l|l|l|l} 
PL & 15 & 25 & 20 & 14 & 7 & 11 & 137
\end{tabular}

$\begin{array}{llllllll}\text { EUR21 } & 252 & 227 & 197 & 176 & 176 & 153 & 1345\end{array}$

Cells tinted pink if numbers of papers $<0.5 \times$ European average for all cardiovascular disease; pale yellow if numbers $<0.71 \times$ average; pale green if $>1.41 \times$ average; bright green if $>2.0 \times$ average. ART $=$ Arterial, $C E R=$ Cerebrovascular, $I S C=$ Ischaemic, $A R R=$ Arrhythmias, $\mathrm{HYP}=$ Hypertension, $\mathrm{FAI}=$ Failure

Table 9: Numbers of papers from health advisory committee members in eight European Member States in asthma and chronic obstructive pulmonary disease, and comparison with total output in all five noncommunicable diseases

\begin{tabular}{lcccc}
\hline Country & AST & COP & All RESPI & Total \\
\hline AT & 8 & 9 & 15 & 673 \\
CZ & 5 & 1 & 6 & 605 \\
DE & 3 & 6 & 15 & 1054 \\
ES & 8 & 33 & 39 & 537 \\
HU & 30 & 8 & 42 & 744 \\
IT & 1 & 4 & 8 & 394 \\
NL & 67 & 38 & 108 & 749 \\
PL & 3 & 3 & 8 & 416 \\
EUR21 & 131 & 107 & 256 & 5713 \\
\hline
\end{tabular}

Cells tinted pink if numbers of papers $<0.5 \times$ European average; pale yellow if numbers. $<0.71 \times$ average; pale green if $>1.41 \times$ average; bright green if $>2.0 \times$ average. $\mathrm{RESPI}=$ Respiratory diseases, $\mathrm{COP}=$ Chronic obstructive pulmonary disease, $\mathrm{AST}=$ Asthma

However, the Netherlands is not so well placed and is as high as sixth (out of 31 countries) in its relative burden from the two diseases. 


\section{DISCUSSION AND CONCLUSIONS}

In this paper, we have compared the research outputs of members of European countries' health advisory committees with their countries' disease burdens. There is an implicit assumption that there should be a correlation, namely that these advisers should be selected on the basis that their expertise should match the clinical needs of the countries. That means that diseases that cause a relatively greater burden should be matched by the presence of expert advisers who know about these diseases (or mental disorders). This would allow them to argue for better treatment facilities for patients. There is also a parallel assumption that a country's biomedical research portfolio should reflect its disease burden, so that it will be better able to treat patients and to take steps to reduce the diseases' incidence.

However, the inverse may also be the case, i.e., that if a country has invested heavily in research on a particular disease for some years, and has health policy advice stemming from this research, this should have led to an improvement in the situation, with fewer patients and better outcomes. This is a kind of "holy grail" of medical research: More research leads to better health. Of course, the links are far more complex than that, and many steps are needed to translate research findings, usually from many different sources, into better treatment for patients and for less illness [Figure 5].

This diagram ${ }^{[30]}$ shows how central "Government policy" is to the provision of better health, and how dependent it is on many different sources. (omits the role of advisory committees, but governments have been known to reject the advice of experts or even to dismiss them if their views are unpalatable. ${ }^{[31]}$ Better health is not just a matter of better clinical care, but economic policy plays a major role too, particularly in the reduction of communicable, maternal, and nutritional diseases through better housing, clean air and water, and good food supplies. In Europe, most of these are available to most of the population (but by no means all) and attention is increasingly being paid to the improvement of "lifestyle choices," such as the reduction of smoking, more exercise and better food choices. Health advisory committees can assist with the selection of government policies that affect all of these though until recently there has been a success on a wide scale only for the discouragement of smoking. This may reflect the focus of advisory committees more on the physical than the social determinants of disease.

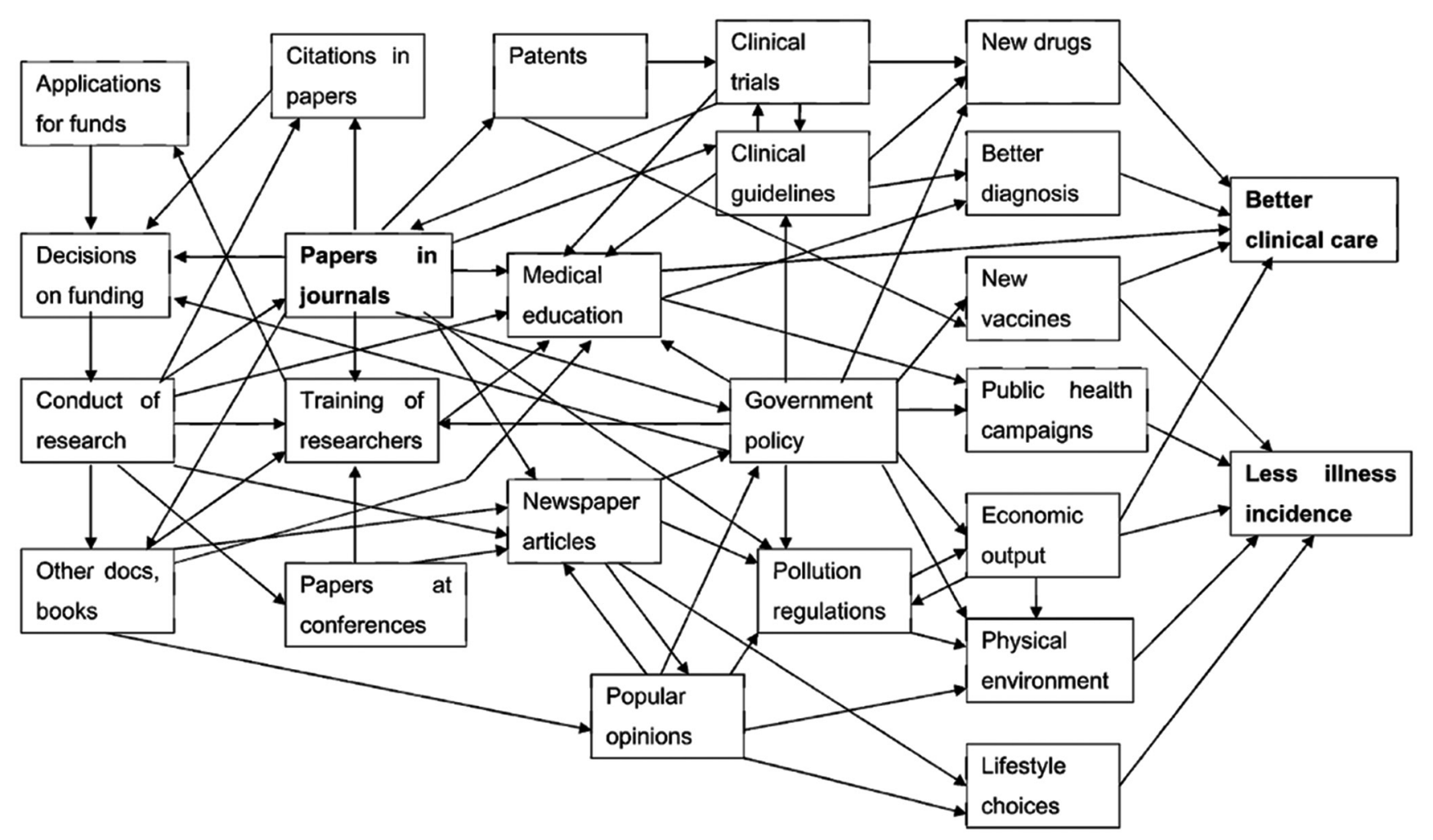

Figure 5: Diagram showing the many linkages between biomedical research and better health ${ }^{[30]}$ 
This study is a preliminary attempt to see how research can feed through into governmental health policy through the members of health advisory committees. It suffers from several limitations. The list of these committees is not complete, and it only gives members at a particular point in time. We have not been able to investigate the personal characteristics of the members, such as age, sex, and background (research or clinical practice or both), because there were so many of them (over 1400). More importantly, we do not know whether the advice that they tendered was actually accepted by their governments and translated into new or revised policies. However, we did observe that the papers in our database were predominantly clinical and biological science rather than social science, and this may be a lacuna that governments need to address if they are to be successful in changing people's habits and lifestyle choices.

\section{Acknowledgments}

We are most grateful to our partners who collected data for us in many different countries and languages. They were: Natalia Kelsch, Tobias Schumacher, Anne Spranger and Victor Stephani in Berlin (Austria, Germany and Switzerland); Eva Nacheva and Christina Tencheva (Bulgaria); Ria Ivandic (Croatia); Kazia Zemanek (Czech Republic and Poland); Maria Dahl and Maria Emilsson (Denmark); Argo Soon (Estonia); Laura Mantovani (Finland); Karen Brigham and Anshoo Lumba in Paris (France); Csajbok Edit in Budapest (Hungary); Ludovica Borsoi in Milan (Italy); Ingrid Jaselskyte in Vilnius (Lithuania); Ann-Sophie de Mol (Luxembourg and the Netherlands); Diana Gosálves-Prados in Grenada (Portugal and Spain); Elisabeth Maria Ilidio-Paulo, Camila Higueras-Callejón and José Carlos Ruiz-Jiménez in Grenada (Portugal); and Elena Salamanca-Fernández in Grenada (Spain).

\section{Financial Support and Sponsorship}

This study was supported by the European Commission under the Seventh Framework Programme.

\section{Conflicts of Interest}

There are no conflicts of interest.

\section{REFERENCES}

1. McDaid S. An equality of condition framework for user involvement in mental health policy and planning: Evidence from participatory action research. Disabil Soc 2009;24:461-74.
2. Gold M. Pathways to the use of health services research in policy. Health Serv Res 2009;44:1111-36.

3. Jansen MW, van Oers HA, Kok G, de Vries NK. Public health: Disconnections between policy, practice and research. Health Res Policy Syst 2010;8:37.

4. El-Jardali F, Lavis JN, Ataya N, Jamal D. Use of health systems and policy research evidence in the health policymaking in eastern Mediterranean countries: Views and practices of researchers. Implement Sci 2012;7:2.

5. Jiang F, Zhang J, Wang X, Shen X. Important steps to improve translation from medical research to health policy. J Transl Med 2013;11:33.

6. Hanney SR, Castle-Clarke S, Grant J, Guthrie S, Henshall C, Mestre-Ferrandiz J, et al. How long does biomedical research take? Studying the time taken between biomedical and health research and its translation into products, policy, and practice. Health Res Policy Syst 2015;13:1.

7. Lomas J, Brown AD. Research and advice giving: A functional view of evidence-informed policy advice in a Canadian ministry of health. Milbank Q 2009;87:903-26.

8. Béland D. Policy change and health care research. J Health Polit Policy Law 2010;35:615-41.

9. Otten JJ, Dodson EA, Fleischhacker S, Siddiqi S, Quinn EL. Getting research to the policy table: A qualitative study with public health researchers on engaging with policy makers. Prev Chronic Dis 2015;12:E56.

10. Ettelt $\mathrm{S}$, Mays $\mathrm{N}$. Health services research in Europe and its use for informing policy. J Health Serv Res Policy 2011;16 Suppl 2:48-60.

11. Volberding P. The impact of HIV research on health outcome and healthcare policy. Ann Oncol 2011;22 Suppl 7:vii50-3.

12. Lavertu $\mathrm{S}$, Weimer DL. Federal advisory committees, policy expertise, and the approval of drugs and medical devices at the FDA. J Public Adm Res Theory 2011;21:211-37.

13. Sauer UG. The role of animal testing advisory committees in biomedical research in Germany. ALTEX 2006;23:29-31.

14. Available from: http://vizhub.healthdata.org/gbd-compare/ [Last accessed in $2015 \mathrm{Apr}]$.

15. Boyack KW, Borner K. Indicator-assisted evaluation and funding of research: Visualizing the influence of grants on the number and citation counts of research papers. J Am Soc Inf Sci Technol 2003;54:447-61.

16. Leydesdorff $\mathrm{L}$. Caveats for the use of citation indicators in research and journal evaluations. J Am Soc Inf Sci Technol 2008;59:278-87.

17. Moed HF. New developments in the use of citation analysis in research evaluation. Arch Immunol Ther Exp (Warsz) 2009;57:13-8.

18. Bornmann $L$, Leydesdorff $L$. The validation of (advanced) bibliometric indicators through peer assessments: A comparative study using data from InCites and F1000. J Informetr 2013;7:286-91.

19. Waltman L, Costas R. F1000 recommendations as a potential new data source for research evaluation: A comparison with citations. J Assoc Inf Sci Technol 2014;65:433-45.

20. Lewison G. The percentage of reviews in research output: A simple measure of research esteem. Res Eval 2009;18:25-37.

21. Grant J, Cottrell R, Cluzeau F, Fawcett G. Evaluating "payback" on biomedical research from papers cited in clinical guidelines: Applied bibliometric study. BMJ 2000;320:1107-11.

22. Lewison G, Wilcox-Jay K. Getting Biomedical Research into Practice: The Citations from UK Clinical Guidelines. Proceedings of the $9^{\text {th }}$ International Conference on Scientometrics and Informetrics, Beijing, China; 2003. p. 152-60.

23. Lewison G, Sullivan R. The impact of cancer research: How publications influence UK cancer clinical guidelines. $\mathrm{Br} \mathrm{J}$ Cancer 2008;98:1944-50.

24. Kryl D, Allen L, Dolby K, Sherbon B, Viney I. Tracking the impact of research on policy and practice: Investigating the feasibility of 
using citations in clinical guidelines for research evaluation. BMJ Open 2012;2:e000897.

25. Lewison G, Tootell S, Roe P, Sullivan R. How do the media report cancer research? A study of the UK's BBC website. Br J Cancer 2008;99:569-76.

26. Lewison G, Roe P, Wentworth A, Szmukler G. The reporting of mental disorders research in British media. Psychol Med 2012;42:435-41.

27. Lewison G, Paraje G. The classification of biomedical journals by research level. Scientometrics 2004;60:145-57.
28. Available from: http://vizhub.healthdata.org/gbd-compare/ [Last accessed in $2015 \mathrm{Apr}$.

30. Lewison G. Beyond SCI citations-new ways to evaluate research. Curr Sci 2005;89:1524-30.

29. Begum M, Lewison G, Wright J, Sullivan R. European NonCommunicable Respiratory Disease Research, 2002-13: Bibliometric study of outputs and funding. PLOS ONE 2016. [In press].

31. Nutt D. Government vs science over drug and alcohol policy. Lancet 2009;374:1731-3. 